Original article

\title{
Surgical treatment and prognosis of breast cancer in elderly - A population-based study
}

\author{
Kaisu Ojala ${ }^{\text {a, * }, ~ T u o m o ~ J . ~ M e r e t o j a ~ a, ~ J o h a n n a ~ M a t t s o n ~}{ }^{\mathrm{b}}$, Marjut H.K. Leidenius ${ }^{\mathrm{a}}$ \\ ${ }^{a}$ Breast Surgery Unit, Comprehensive Cancer Centre, Helsinki University Hospital and Helsinki University, Finland \\ ${ }^{\mathrm{b}}$ Department of Oncology, Comprehensive Cancer Centre, Helsinki University Hospital and Helsinki University, Finland
}

\section{A R T I C L E I N F O}

Article history:

Accepted 16 January 2019

Available online $\mathrm{xxx}$

\section{Keywords:}

Breast cancer

Elderly

Surgery

\begin{abstract}
A B S T R A C T
Background: The aim of this study was to investigate outcome of treatment in patients over 80 years of age with early breast cancer at the time of the diagnosis with special interest in surgical treatment. Materials and methods: Breast cancer patients older than 80 years of age, treated at the Breast Surgery Unit of Helsinki University Hospital in 2005-2010 were identified from electronic patient records. Patients were followed-up until the end of 2014. Patient and tumour characteristics, recurrences, comorbidities and reasons for omission of surgery were collected from electronic patient records. Survival data was obtained from Finnish Cancer Registry.

Results: 446 patients were eligible for the study: 401 (90\%) received surgery. The median follow-up time was 52 months. In the entire study population, local and regional recurrences/disease progression were diagnosed in $16(3.6 \%)$ and $6(1.3 \%)$ patients, respectively. The five-year overall survival was $50.6 \%$ in the surgical treatment and only $15.2 \%$ in non-surgical treatment group, $\mathrm{p}<0.001$. Also, the five-year breast cancer specific survival was significantly better in the patients with surgery, $82.0 \%$, but $56.0 \%$ in the patients without surgery, $\mathrm{p}<0.001$. There was no mortality related to the surgery, but $122(30 \%)$ patients died within three years from surgery.

Conclusion: Surgical treatment rate was high. OS and BCSS were better in surgically treated elderly patients. Local and regional disease control was excellent, probably due to high rate of surgical treatment. Surgical treatment also seemed safe in this elderly patient population. However, surgical overtreatment was obvious in some patients.
\end{abstract}

(c) 2019 Elsevier Ltd, BASO The Association for Cancer Surgery, and the European Society of Surgical Oncology. All rights reserved.

\section{Introduction}

The number of elderly breast cancer patients in clinical practice increases due to aging of the population in developed countries [1]. The incidence of breast cancer in the elderly patients in Finland is high: under a five-year period from 2011 to 2015 the incidence was 221 per 100000 women in age group 80-85 years and 247 per 100000 in age group 85 years and older. Altogether 3179 women aged 80 years or older were diagnosed with primary breast cancer in Finland between 2011 and 2015 (Finnish Cancer Registry (cancerregistry.fi)).

Treatment guidelines are less often followed in elderly breast cancer patients [2-6]. Also, treatment strategies of early breast

\footnotetext{
* Corresponding author. Töölö Hospital, P.O.Box 266, 00029, HUS, Finland.

E-mail address: Kaisu.ojala@hus.fi (K. Ojala).
}

cancer vary markedly both nationally and internationally. In two recent studies, elderly patient populations from European countries were compared [7,8]. These studies found a great variance in treatment: in the British population $47.8 \%$ of patients received surgery in comparison to $90.5 \%$ in the Dutch population [7]. The Finnish National Guideline recommends that breast cancer patients should be treated similarly, regardless the chronological age. However, the extend of surgery can be adjusted according to general condition and co-morbidities among the elderly patients. Not only overall survival (OS) but also breast cancer specific survival (BCSS) have been inferior in elderly breast cancer patients, when compared to younger patients. Impact of adjuvant radiotherapy (RT) on survival and local recurrences has been investigated [9-11], but there is less evidence regarding benefit of surgery on local disease control and survival in elderly breast cancer patients [12].

For these reasons, our aim was to investigate the treatment outcome in patients over 80 years of age with early breast cancer, in 
a population-based setting with special interest in surgical treatment.

\section{Material and methods}

Breast cancer patients older than 80 years of age, treated at the Breast Surgery Unit, Comprehensive Cancer Centre of the Helsinki University Hospital, between January 1st' 2005 and December 31st' 2010 were identified retrospectively from electronic patient records using ICD-10 diagnoses codes C50 and D05. Our unit is a population-based centre, providing surgical treatment of breast cancer for the Uusimaa region of Finland, with a population of up to 1.6 million. Treatment of malignant diseases is almost exclusively performed by public health care system in Finland. We consider this study population-based since patients are referred to certain hospital based solely on their place of residence.

A total of 552 patients were identified. Of these, 106 were excluded: 25 patients had recurrent breast cancer, 62 had received primary surgery or other cancer treatments before study period, six patients had other malignancy than breast cancer in the breast, nine patients had benign breast tumour and four patients were treated for post-operative problems due to an earlier breast cancer operation. Altogether, the study population included 446 patients older than 80 years of age, with primary early breast cancer at the time of the diagnosis. Data was collected from patient records and the Finnish Cancer Registry database.

Recorded variables included age, co-morbidities, diagnostic procedures, tumour characteristics, surgery performed, adjuvant treatments, reasons for omitting surgery or other treatment, breast cancer recurrences, survival status, date and cause of death. Comorbidities were classified as ischemic heart disease, other severe cardio-vascular disease, pulmonary disease, hypertension, diabetes, dementia and other severe disease (i.e. rheumatoid arthritis, other active malignancy). Similarly, reasons for omitting surgery or other recommended treatment were also recorded, as well as patient's preference concerning treatment. Follow-up period ended in December 31st' 2014 and patients' survival status (alive, breast cancer related death, death for other cause) at that date was obtained from Finnish Cancer Registry.

Mammography and/or ultrasound were performed according to Finnish breast cancer diagnostic guideline. Needle biopsy was taken and core needle biopsy was preferred. If axillary lymph node involvement was suspected, fine needle aspiration cytology was taken. Experienced breast surgeons evaluated patient's general condition as well as the clinical stage of the cancer, but no geriatric assessment scale was used. Eligibility for general anaesthesia was assessed by the anaesthesiologists. Local anaesthesia was an option for general anaesthesia in selected cases while no other options (nerve blocs for example) were not available. Oestrogen receptor status was included in the decision making in patients who were not eligible for general anaesthesia or unwilling to undergo surgery. Preoperative staging imaging like CT scan or bone scan were performed only in patients with symptoms suspicious for distant metastases. Final treatment decision was made in agreement with patient and/or her family member.

Breast and axillary surgery was performed or supervised by expert breast surgeons. In patients with breast conservation, wide local tumour excision was performed aiming at $1 \mathrm{~cm}$ tumour free lateral margins and including the underlying pectoral fascia and a slice of the overlying skin in the resected specimen. Sentinel node biopsy (SNB) and axillary lymph node dissection (ALND) or both were performed as described in our previous study [13]. The breast surgery specimens were oriented by surgeon and sent unfixed to the pathology laboratory. Tumour characteristics were assessed by specialized breast pathologist. Sentinel nodes and the nodes from the axillary lymph node dissection specimen were assessed as described by Meretoja et al. [14].

Adjuvant treatment recommendations were made in the multidisciplinary meeting. In general, estimated recurrence rate of over $10 \%$ in ten-year time was considered as threshold value for systemic endocrine treatment. Adjuvant chemotherapy was not recommended in this series of patients being over 80 years of age. Patient co-morbidities, general condition and age were also taken into account. Similarly, eligibility for RT was evaluated.

Post-operative CT-scan was generally recommended in patients with histological pT3-T4 disease and in those with histological stage pN2-3 nodal disease. Follow-up was accomplished according to an individually planned schedule. In addition, all patients had access to an outpatient unit whenever there was concern of breast cancer recurrence or side-effects/morbidity of the treatment.

This study was approved by the Surgical Ethics Committee of the Helsinki and Uusimaa Hospital district.

\section{Statistical methods}

Frequency tables were analysed using the chi-squared test and continuous distributions were compared with the Mann Whitney $U$ test. Distant disease-free survival (DDFS) was calculated from the date of diagnoses to the date of first occurrence of breast cancer metastases outside of regional lymph nodes. The BCSS was calculated from the date of diagnoses to the date of death considered to result from breast cancer, and the OS from the date of diagnoses to the date of death from any cause. Patients alive without any cancer recurrence were censored on the completion date of the follow-up period.

Life tables were analysed using Kaplan-Meier method, and survival between groups was compared with the log-rank test. Statistical analyses were performed using IBM SPSS statistics version 22 (SPSS Inc, Chicago, IL) software.

\section{Results}

\section{Patient characteristics}

The median age of patients was 84.5 years (range 80.0-101.9 years). Of these, 241 (54.0\%) patients were from 80.0 to 84.9 years of age, 145 (32.5\%) patients from 85.0 to 89.9 years and $60(13.5 \%)$ patients were over 90 years of age. The median age of patients receiving surgery was 84.1 years (range $80.0-101.9$ years) and of those not receiving surgery 86.5 years (range $82.2-90.8$ years), $\mathrm{p}=0.347$. The tumour characteristics are shown in Table 1. 384 (86.1\%) patients had one or more co-morbidities: 254 (57.0\%) had hypertension, 120 (27.0\%) had ischemic cardiac disease, 147 (33.0\%) had other severe cardio-vascular diseases (i.e. atrial fibrillation, atherosclerosis), 65 (14.6\%) had diabetes, 57 (12.8\%) had dementia, 42 had (9.4\%) pulmonary disease and 123 (37.0\%) had some other severe disease such as rheumatoid arthritis, kidney failure or psychiatric disease. In 94 (21.1\%) cases, the general condition of the patient influenced the treatment decision. Patient preference influenced the treatment in 43 (9.6\%) cases.

\section{Patients with surgery}

Surgery of the primary tumour was performed in 401 patients (90.0\%). Twelve (3\%) patients underwent surgery under local anaesthesia. Axillary surgery was performed in $352(78.1 \%)$ patients (Table 2). Altogether 32 (26.2\%) patients undergoing ALND without preceding SNB were axillary node negative. In 38 (9.5\%) patients, general condition affected surgical treatment: less extensive surgery than generally recommend, was performed. Fifteen (3.7\%) 
Table 1

Tumour characteristics.

\begin{tabular}{|c|c|c|c|c|c|}
\hline & & \multicolumn{2}{|c|}{ Patients with surgery $n=401$} & \multicolumn{2}{|c|}{$\begin{array}{l}\text { Patients without surgery } \\
\mathrm{n}=45\end{array}$} \\
\hline & & $\mathrm{N}$ & $\%$ & $\mathrm{~N}$ & $\%$ \\
\hline \multirow[t]{6}{*}{$\mathrm{p} / \mathrm{c}$ T stage ${ }^{\mathrm{a}}$} & Tis & 13 & $3.2 \%$ & 2 & $4.4 \%$ \\
\hline & $\mathrm{T} 1$ & 190 & $47.4 \%$ & 17 & $37.8 \%$ \\
\hline & $\mathrm{T} 2$ & 174 & $43.4 \%$ & 20 & $44.4 \%$ \\
\hline & T3 & 17 & $4.3 \%$ & 0 & \\
\hline & $\mathrm{T} 4$ & 5 & $1.2 \%$ & 4 & $8.9 \%$ \\
\hline & NA & 2 & $0.5 \%$ & 2 & $4.4 \%$ \\
\hline \multirow[t]{6}{*}{$\mathrm{p} / \mathrm{c} \mathrm{N}$ stage ${ }^{\mathrm{a}}$} & NO & 187 & $46.5 \%$ & 0 & \\
\hline & NOmi & 7 & $1.7 \%$ & 0 & \\
\hline & $\mathrm{N} 1$ & 92 & $22.9 \%$ & 2 & $4.4 \%$ \\
\hline & N2 & 34 & $8.5 \%$ & 0 & \\
\hline & N3 & 32 & $8.0 \%$ & 0 & \\
\hline & NA & 49 & $12.4 \%$ & 43 & $95.6 \%$ \\
\hline \multirow[t]{4}{*}{ Histological grade } & 1 & 79 & $19.2 \%$ & 5 & $11.1 \%$ \\
\hline & 2 & 151 & $37.7 \%$ & 4 & $8.9 \%$ \\
\hline & 3 & 156 & $39.0 \%$ & 4 & $8.9 \%$ \\
\hline & NA & 15 & $3.7 \%$ & 32 & $80.0 \%$ \\
\hline \multirow[t]{3}{*}{ Multifocality } & No & 262 & $65.3 \%$ & 40 & $88.9 \%$ \\
\hline & Yes & 69 & $17.2 \%$ & 5 & $11.1 \%$ \\
\hline & NA & 70 & $17.5 \%$ & 0 & \\
\hline \multirow[t]{3}{*}{ ER } & negative & 48 & $12.0 \%$ & 2 & $4.4 \%$ \\
\hline & positive & 337 & $84.0 \%$ & 33 & $73.3 \%$ \\
\hline & NA & 16 & $4.0 \%$ & 10 & $22.2 \%$ \\
\hline \multirow[t]{3}{*}{ PR } & negative & 137 & $34.1 \%$ & 9 & $20.0 \%$ \\
\hline & positive & 245 & $61.1 \%$ & 24 & $53.3 \%$ \\
\hline & NA & 19 & $4.7 \%$ & 12 & $26.7 \%$ \\
\hline \multirow[t]{3}{*}{ HER2 } & negative & 320 & $79.8 \%$ & 21 & $46.7 \%$ \\
\hline & positive & 37 & $9.2 \%$ & 2 & $4.4 \%$ \\
\hline & NA & 44 & $11.0 \%$ & 22 & $48.9 \%$ \\
\hline \multirow[t]{5}{*}{ Tumour type } & DCIS & 13 & $3.2 \%$ & 2 & $4.4 \%$ \\
\hline & ductal & 281 & $70.1 \%$ & 13 & $28.9 \%$ \\
\hline & lobular & 60 & $15.0 \%$ & 7 & $15.6 \%$ \\
\hline & Other invasive & 44 & $11.0 \%$ & 7 & $15.6 \%$ \\
\hline & invasive cancer, not specified & 3 & $0.7 \%$ & 16 & $35.6 \%$ \\
\hline
\end{tabular}

NO includes patients with isolated tumour cells in the sentinel node.

a $\mathrm{T}$ stage and $\mathrm{N}$ stage: pathological stage in operated patients, clinical stage in non-operated patients.

Table 2

Surgical and post-operative adjuvant treatment.

\begin{tabular}{lll}
\hline & $\mathrm{n}$ & $\%$ \\
\hline $\begin{array}{l}\text { Breast surgery } \mathbf{n}=\mathbf{4 0 1} \\
\text { wide local excision } \\
\text { oncoplastic resection } \\
\text { mastectomy }\end{array}$ & 115 & \\
Axillary surgery & 2 & $28.7 \%$ \\
SNB & 284 & $0.5 \%$ \\
ALND & & $70.8 \%$ \\
SNB and ALND & 155 & $38.7 \%$ \\
No Axillary surgery & 120 & $30.0 \%$ \\
Adjuvant treatment n=302 & 77 & $19.2 \%$ \\
RT after BCS & 49 & $12.2 \%$ \\
RT after mastectomy & & \\
Endocrine therapy & 66 & $21.9 \%$ \\
Chemotherapy & 68 & $22.5 \%$ \\
\hline
\end{tabular}

SNB: sentinel node biopsy. ALND: axillary lymph node dissection. RT: radiotherapy $\mathrm{BCS}$ : breast conserving surgery.

patients received mastectomy in order to avoid RT.

Adjuvant treatments were given to 302 (75.3\%) patients (Table 2). In 26 (6.3\%) cases, the general condition of the patient influenced the adjuvant treatment recommended by the oncologist. Notably, adjuvant chemotherapy was not recommended in patients over 80 years of age according to treatment guidelines. Patient's preference changed the recommended adjuvant

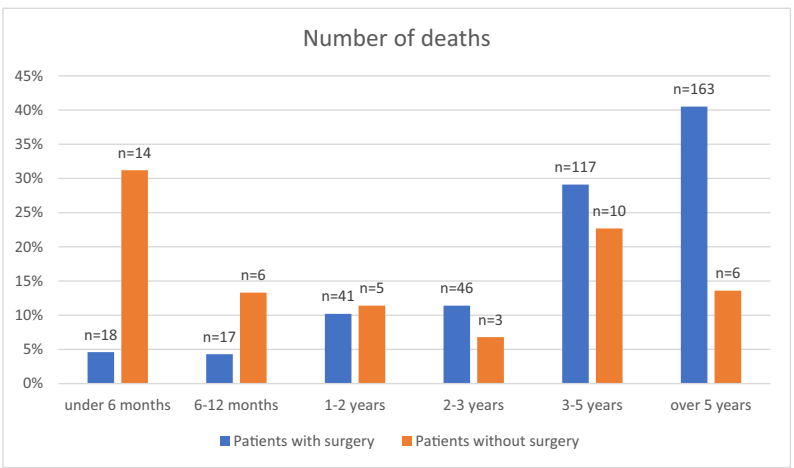

Fig. 1. Number of deaths by treatment groups.

treatment in 37 (12.3\%) cases: 30 patients refused RT and 7 patients refused endocrine treatment. None of the patients received neoadjuvant treatment.

\section{Patients without surgery}

Surgery was not performed in 45 (10.1\%) patients. Surgery was omitted due to poor general condition in $31(69 \%)$ of these patients. Nine $(20 \%)$ patients refused surgery. In five (11\%) patients, the 
reason for omission of surgery was not clearly stated in the patient records. As regards to co-morbidities, patients without surgery had more often ischemic heart disease (20 [44.4\%] vs. 101 [25.2\%], $\mathrm{p}=0.006$ ) and dementia ( $11[24.4 \%]$ vs. 46 [11.4\%], $\mathrm{p}=0.013$ ) when compared to patients with surgery. There were no statistically significant differences between surgical and non-surgical treatment groups in the other recorded co-morbidities. Endocrine therapy was given to 33 (73.3\%) of the patients without surgery. None of the patients without surgery received RT or chemotherapy. Twelve (26.7\%) patients did not receive any oncological treatment. Reasons for omitting treatment were very poor general condition in

a

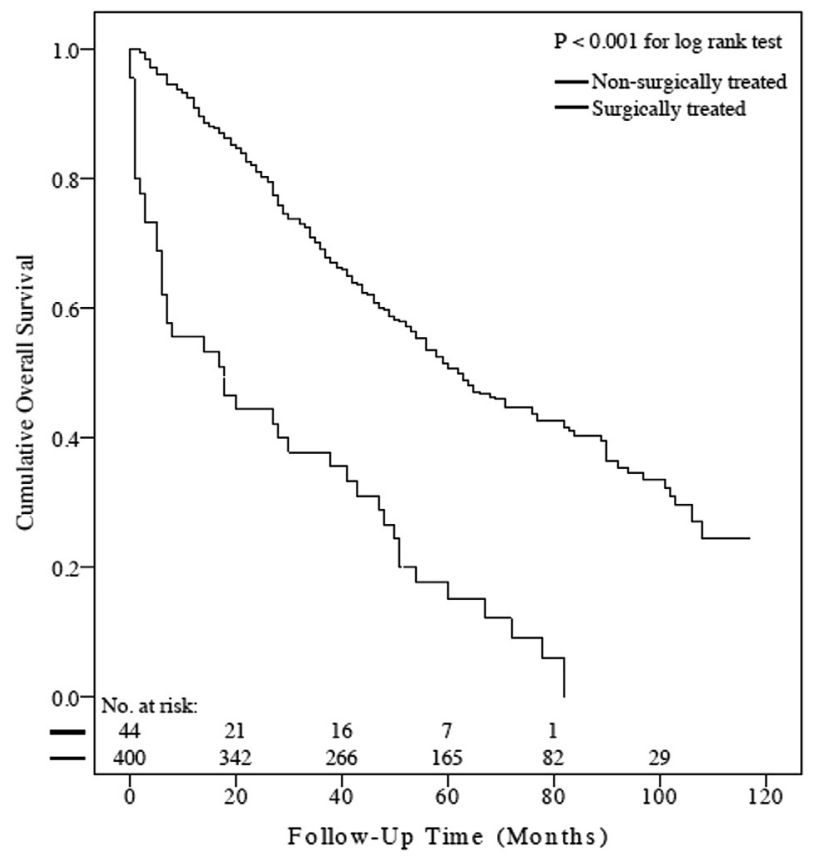

nine cases and patient's preference in two cases. In one case, the reason for omitting treatment was not clear from the patient records.

\section{Recurrences and survival}

Survival

For all patients, the median follow-up period was 52 months (range 0-117 months). For surgically treated patients, the median follow-up was 54 months (range 1-117 months) and for patients

b

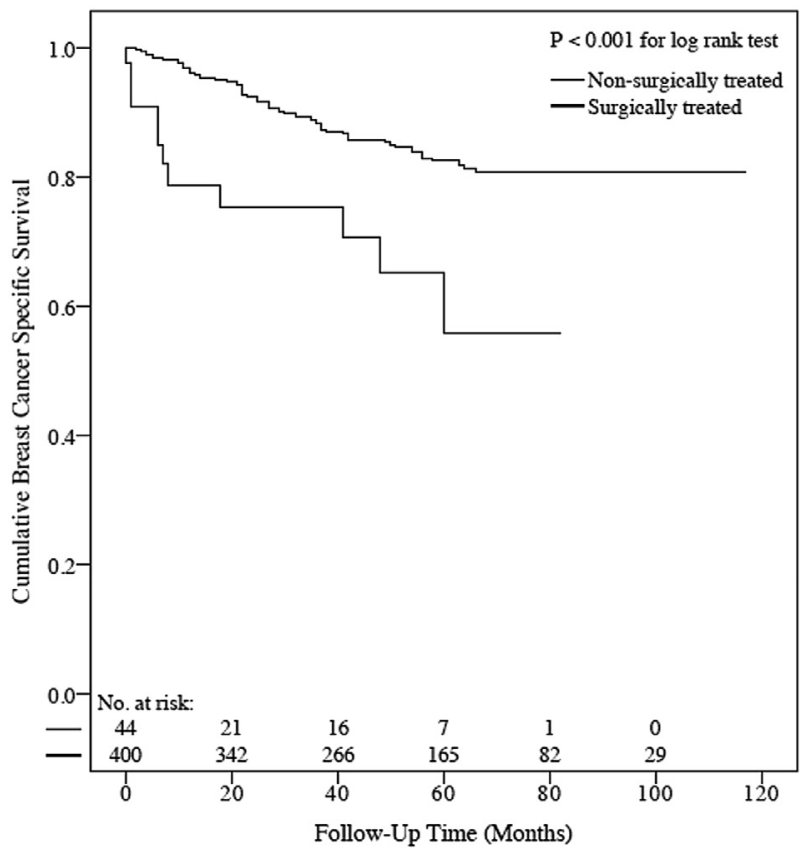

C

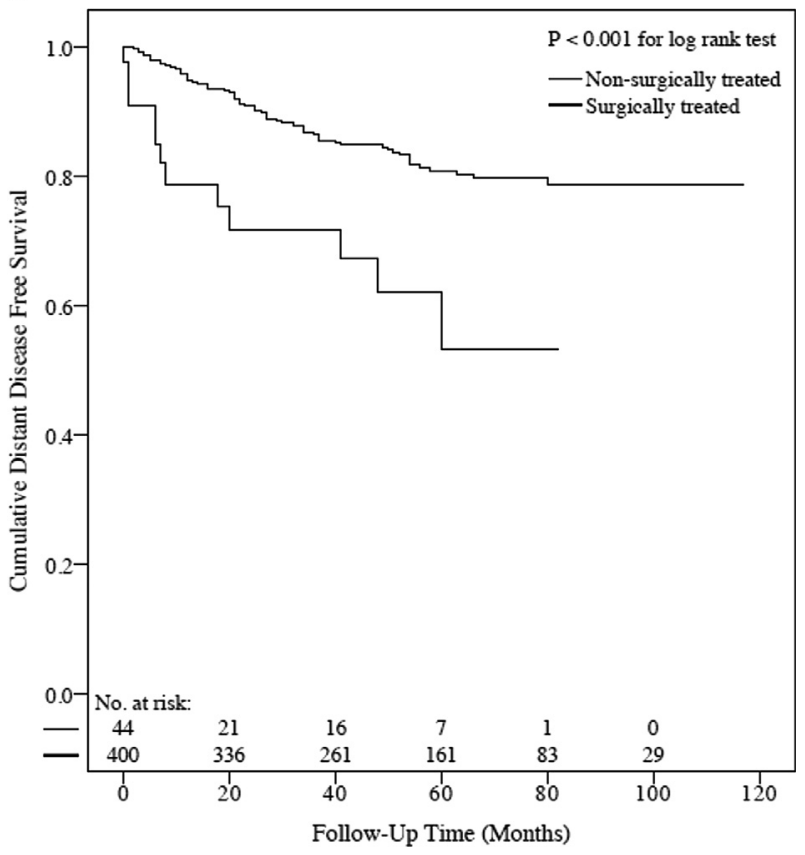

Fig. 2. a. Overall survival. Comparison between surgical and non-surgical treatment groups.

b. Breast cancer specific survival. Comparison between surgical and non-surgical treatment groups.

c. Distant disease-free survival. Comparison between surgical and non-surgical treatment groups. 
Table 3

Breast cancer events observed during follow up according to treatment groups.

\begin{tabular}{|c|c|c|c|c|}
\hline & & \multirow{2}{*}{$\frac{\text { With Surgery }}{\mathrm{N}=401(\%)}$} & \multirow{2}{*}{$\frac{\text { Without Surgery }}{\mathrm{N}=45(\%)}$} & \multirow[b]{2}{*}{$p(\log$ rank $)$} \\
\hline & & & & \\
\hline \multirow[t]{2}{*}{ Follow-up (months) } & Median & 54 & 18 & \\
\hline & range & $1-117$ & $0-82$ & \\
\hline \multirow[t]{6}{*}{ Events } & Local recurrence & $16(4 \%)$ & 0 & 0.298 \\
\hline & Contralateral breast cancer & 0 & 0 & \\
\hline & Regional lymph node recurrence & $5(1 \%)$ & $1(2 \%)$ & 0.218 \\
\hline & Distant metastasis & $67(17 \%)$ & $13(29 \%)$ & $<0.001$ \\
\hline & Breast cancer death & $61(15 \%)$ & $12(27 \%)$ & $<0.001$ \\
\hline & Death from other cause & $165(41 \%)$ & $30(67 \%)$ & $<0.001$ \\
\hline
\end{tabular}

without surgery, it was 18 months (range $0-82$ months). Overall 226 (56\%) patients receiving surgery died during follow-up. Of these 226 deaths, 61 (27\%) deaths were breast cancer related. None of the operated patients died within 30 days from surgery.

Eighty-one patients with surgery had either histopathological T3-4 or N2-3 disease or both. Forty-one of them had post-operative CT-scan. Nine patients had distant metastases diagnosed in their CT-scans. Four of these nine patients died in breast cancer 3-55 months after diagnosis, three patients died in causes unrelated to breast cancer and 2 were alive at the end of the follow-up for 49and 83 months.

Of the non-surgically treated patients, 42 (93\%) died during follow-up. Twelve of them (29\%) died of breast cancer (Fig. 1).

The five-year OS was $50.6 \%$ in the surgical treatment group and $15.2 \%$ in non-surgical treatment group, $\mathrm{p}<0.001$ (Fig. 2a). The fiveyear BCSS was $82.0 \%$ in patients with surgery and $56.0 \%$ in patients without surgery, $\mathrm{p}<0.001$ (Fig. 2b).

\section{Recurrences}

In the entire study population, local and regional recurrences/ disease progression were diagnosed in 16 (3.6\%) and 6 (1.3\%) patients, respectively. The median time from diagnosis to local recurrence/disease progression was 13 months (range 3-49 months) and to regional lymph node recurrence 35 months (range 7-61 months). Distant metastases were reported in 80 (17.9\%) patients. The median time from the primary diagnosis to distant metastases was 51 months (range 0-117 months), including the nine patients with distant metastases diagnosed in the postoperative CT scan. Five-year DDFS was $80.4 \%$ in patients with surgery and $53.3 \%$ in patients without surgery, $\mathrm{p}<0.001$, Fig. $2 \mathrm{c}$. Number of breast cancer events by treatment groups is displayed in Table 3.

\section{Discussion}

Local treatment, that is radiotherapy and especially surgery, is the cornerstone of the treatment in early breast cancer, also among the elderly. In this population-based study covering a large region of Finland, surgical treatment rate was higher than in many previous studies [2,12,15-17]. Patients receiving surgical treatment had better OS when compared with patients without surgical treatment. Also, BCSS was significantly better in the surgically treated patients.

The observed better survival in patients with surgery may also be due to selection bias, at least in part. Although no geriatric assessment scale was used, patients with a short life expectancy were less likely to receive surgical treatment. Accordingly, deaths from any cause during the first year from diagnosis were more frequent in patients without surgery, confirming successful patient selection when omitting surgical treatment.
Altogether 122 (30\%) patients in the surgical treatment group died within three years from surgery, and 35 of them died within first year after surgery. Most of the deaths were for other causes than breast cancer. Presumably these patients didn't have survival benefit from surgery and can be considered as over-treated. On the other hand, 61 (15\%) surgically treated patients died of breast cancer during the follow-up. More aggressive systemic treatment, that is chemotherapy, could improve survival. Previous studies report decreased use of chemotherapy and marked variation among elderly $[6,18,19]$. Chemotherapy in elderly is may be as effective as in younger patients, but with a higher risk of toxicity [6]. However, the definition of elderly varies in the studies and there is not much evidence addressing the benefit of chemotherapy in adjuvant setting in patients older than 80 years.

One of the most important aims of breast cancer treatment in elderly is the local disease control. In our study, 18 out of 122 surgically treated patients had ER negative cancer and died within three years from surgery. These patients may have benefited from surgery in terms of local disease control, even though surgery did not provide survival benefit. Even in elderly patients with hormone receptor positive cancer, primary endocrine treatment as an alternative to primary surgery has been proven to result in inferior local disease control [20-22]. After failed primary endocrine treatment, more extensive surgery - that is mastectomy - may be needed. Therefore, local disease progression could affect seriously quality of life, which is of major importance also in elderly patients. Moreover, advanced age, co-morbidities and frailty - all reasons for considering non-surgical treatment - affect patient's ability to tolerate endocrine treatment and lead to a poor quality of life and decrease in compliance.

In the present study, proportion of mastectomies was high. Similar trend towards more extensive procedures in elderly can be seen in previous studies [15-17,23,24]. Mastectomy has adverse effects: imbalance due to remaining heavy breast can cause functional impairment, post-operative seroma formation is more common and self-evidently aesthetic outcome is worse. Aesthetic outcome after breast cancer surgery may be less important in elderly patients but impairment of functional status should be considered carefully in this patient group to avoid negative effects in terms of quality of life.

Mastectomy was also performed to avoid RT after breast conserving surgery (BCS). Previous studies have clearly shown that RT after BCS does not provide survival benefit but lowers the risk of local recurrence also in elderly women [10,22,24-28]. On the other hand, adverse effects of RT may also be more common in elderly population [25]. For these reasons, mastectomy should not be routinely performed, when RT after breast conservation cannot be given due to poor general condition or due to patient preference.

In our study, $88 \%$ of surgically treated elderly patients received axillary staging - that is markedly more often than in previous studies $[23,29,30]$. However, the proportion of node negative 
patients undergoing ALND was high, due to an old treatment policy applied during the study period. During and after the study period, indications for SNB have extended rapidly while indications for upfront ALND decreased.

Breast surgeons and other members of the multidisciplinary team have an important role in tailoring the treatment [4,5,31]. However, evaluating life-expectancy even in the presence of serious co-morbidities is difficult. Functionality and quality of life in elderly may persist on same level for years despite various comorbidities and frailty. Geriatric assessment tools may provide additional useful information for decision making. According to recent research, usability of geriatric assessment tools in clinical practice is suboptimal and needs further development [32-34].

It is noteworthy, that elderly patients are less likely to search information from other sources such as internet and may rely strongly on physician's recommendations. Interestingly, in a study by Shumway et al. [5], nearly half of the surgeons and radiation oncologists reported that it takes more effort to advise a patient that they don't need RT than it does to recommend it. Thus, in fact, patient's decision of treatment may actually reflect physician's preference and attitude.

The major limitation of this study was the selection bias possibly affecting the results. Neither any geriatric assessment tools were used in clinical decision making; ASA classification might have given more information of general condition of patients but was not available in electronic patient records. Therefore, co-morbidities could not be classified for multivariate analyses. The retrospective study setting also influenced the accuracy of the data collections, for example regarding reasons to omit post-operative CT-scan in so many patients with $\mathrm{T} 3-4$ or N2-N3 diseases. Moreover, comparing BCSS between groups may not be reliable since it was not adjusted according to $\mathrm{T}$ and $\mathrm{N}$ stages neither according to the tumour biology.

\section{Conclusions}

OS and BCSS were better in surgically treated breast cancer patients older than 80 years. Local and regional disease control was excellent, probably due to high rate of surgical treatment. Surgical treatment was safe in this elderly patient population. However, surgical overtreatment was obvious. Therefore, better evidencebased selection criteria for surgical and non-surgical treatment in elderly breast cancer patients are needed.

\section{Conflict of interest}

None.

\section{Funding}

KO and TMJ were supported by Cancer Foundation Finland sr.

\section{Acknowledgements}

KO and TJM were supported by Cancer Foundation Finland sr.

\section{References}

[1] Global Burden of Disease Cancer Collaboration. Global, regional, and national cancer incidence, mortality, years of life lost, years lived with disability, and disability-adjusted life-years for 32 cancer groups, 1990 to 2015: a systematic analysis for the global burden of disease study. JAMA Oncol 2017;3(4): 524-48.

[2] van de Water W, Bastiaannet E, Dekkers OM, de Craen A, Westendorp RGJ, Voogd AC, et al. Adherence to treatment guidelines and survival in patients with early-stage breast cancer by age at diagnosis. Br J Surg 2012;99(6): 813-20.
[3] Kiderlen M, Ponti A, Tomatis M, Boelens PG, Bastiaannet E, Wilson R, et al Variations in compliance to quality indicators by age for 41,871 breast cancer patients across Europe: a European Society of Breast Cancer Specialists database analysis. Eur J Cancer 2015;51(10):1221-30.

[4] Angarita FA, Chesney T, Elser C, Mulligan AM, McCready DR, Escallon J. Treatment patterns of elderly breast cancer patients at two Canadian cancer centres. EJSO 2015;41(5):625-34.

[5] Shumway D, Griffith K, Sabel M, Jones R, Forstner J, Bott-Kothari T, et al Surgeon and radiation oncologist views on omission of adjuvant radiotherapy for older women with early-stage breast cancer. Ann Surg Oncol 2017;24: 3518-26.

[6] Biganzoli L, Wildiers H, Oakman C, Marotti L, Loibl S, Kunkler I, et al. Management of elderly patients with breast cancer: updated recommendations of the international society of geriatric oncology (SIOG) and european society of breast cancer specialists (EUSOMA). Lancet Oncol 2012;13(4):e148-60.

[7] Schuil H, Derks M, Liefers G-J, Portielje J, van de Velde C, Syed B, et al. Treatment strategies and survival outcomes in older women with breast cancer: a comparative study between the FOCUS coort and Nottingham cohort. J Geriatr Oncol 2018. https://doi.org/10.1016/j.jgo.2018.05.004.

[8] Derks MGM, Bastiaannet E, Kiderlen M, Hilling DE, Boelens PG, Walsh PM, et al. Vatiation in treatment and survival of older patients with non-metastatic breast cancer in five European countries: a population-based cohort study from the EURECCA Breast Cancer Group. BJC 2018. https://doi.org/10.1038/ s41416-018-0090-1.

[9] Matuchek C, Bölke E, Haussman J, Mohrman S, Nestle-Krämling C, Gerber PA, et al. The benefit of adjuvant radiotherapy after breast conserving surgery in older patients with loe risk breast cancer - a meta-analysis of randomized trials. Radiat Oncol 2017;12:60-8.

[10] Early breast cancer trialists' collaborative group. Effect of radiotherapy after breast-conserving surgery on 10-year recurrence and 15-year breast cancer death: meta-analysis of individual patient data for 10801 women in 17 randomized trials. Lancet 2011;373:1707-16.

[11] van de Water W, Bastiaannet E, Scholten A, Kiderlen M, de Craen A, Westendorp R, et al. Breast-conserving surgery with or without radiotherapy in older breast patients with early stage breast cancer: a systemic review and meta-analysis. Ann Surg Oncol 2014;21:786-94.

[12] Hamaker ME, Bastiaannet E, Evers D, Wvd Water, Smorenburg CH, Maartense E, et al. Omission of surgery in elderly patients with early stage breast cancer. Eur J Cancer 2013;49(3):545-52.

[13] Leikola JP, Toivonen TS, Krogerus LA, von Smitten KA, Leidenius MH. Rapid immunohistochemistry enhances the intraoperative diagnosis of sentinel lymph node metastases in invasive lobular breast carcinoma. Cancer 2005; 104(1):14-9.

[14] Meretoja TJ, Vironen JH, Heikkilä Päivi S, Leidenius MH. Outcome of selected breast cancer patients with micrometastasis or isolated tumor cells in sentinel node biopsy and no completion axillary lymph node dissection. J Surg Oncol 2010;102(3):215-9.

[15] Sierink JC, de Castro SMM, Russell NS, Geenen MM, Steller EP, Vrouenraets BC Treatment strategies in elderly breast cancer patients: is there a need for surgery? Breast 2014;23(6):793-8.

[16] Eaker S, Dickman PW, Bergkvist L, Holmberg L. The uppsala/örebro breast cancer group. Differences in management of older women influence breast cancer survival: results from a population-based database in Sweden. PLoS Med 2006;3(3):e25.

[17] Kiderlen M, van de Water W, Bastiaannet E, de Craen AJM, Westendorp RG van de Velde CJH, et al. Survival and relapse free period of 2926 unselected older breast cancer patients: a FOCUS cohort study. Cancer Epidemiol 2015;39(1):42-7.

[18] van Leeuwen BL, Rosenkranz KM, Lei LL, Bedrosian I, Hartmann K, Hunt KK, et al. The effect of under-treatment of breast cancer in women 80 years of age and older. Crit Rev Oncol-Hematol 2011;79:315-20.

[19] Weggelaar I, Aben KK, Warlé MC, Strobbe LJ, van Spronsen DJ. Declined guideline adherence in older breast cancer patients: a population-based study in The Netherlands. Breast 2011;17:239-45.

[20] Hind D, Wyld L, Beverley C, Reed MW. Cochrane Database Syst Rev 2006;1: CD004272.

[21] Syed BM, Al-Khyatt W, Johnston SJ, Wong DW, Winterbottom L, Kennedy H, et al. Long-term clinical outcome of oestrogen receptor-positive operable primary breast cancer in older women: a large series from a single centre. $\mathrm{Br}$ J Canc 2011;104(9):1393-400.

[22] Hughes KS, Schnaper LA, Bellon JR, Cirrincione CT, Berry DA, McCormick B et al. Lumpectomy plus tamoxifen with or without irradiation in women age 70 Years or older with early breast cancer: long-term follow-up of CALGB 9343. JCO 2013;31(19):2382-7.

[23] van de Water W, Markopoulos C, van de Velde CJH, Seynaeve C, Hasenburg A, Rea D. Association between age at diagnosis and disease-specific mortality among postmenopausal women with hormone receptor-positive breast cancer. JAMA 2012;307:590-7.

[24] Besic N, Besic H, Peric B, Pilko G, Petric R, Zmuc J, et al. Surgical treatment of breast cancer in patients aged 80 years or older-how much is enough? BMC Canc 2014; $14: 700-7$.

[25] Early breast cancer trialists' collaborative group. Favourable and unfavourable effects on long-term survival of radiotherapy for early breast cancer: an overview of the randomized trials. Lancet 2000;355:1757-70.

[26] Tinterri C, Gatzemeier W, Costa A, Gentilini MA, Zanini V, Regolo L, et al 
Breast-conservative surgery with and without radiotherapy in patients aged 55-75 years with early-stage breast cancer: a prospective, randomized, multicenter trial analysis after 108 months of median follow-up. Ann Surg Oncol 2014;21(2):408-15.

[27] Tinterri C, Gatzemeier W, Zanini V, Regolo L, Pedrazzoli C, Rondini E, et al. Conservative surgery with and without radiotherapy in elderly patients with early-stage breast cancer: a prospective randomised multicentre trial. Breast 2009;18(6):373-7.

[28] Kunkler IH, Williams LJ, Jack WJ, Cameron DA, Dixon JM. Breast-conserving surgery with or without irradiation in women aged 65 years or older with early breast cancer (PRIME II): a randomised controlled trial. Lancet Oncol 2015;16(3):266-73.

[29] van Wely B, Teerenstra S, Schinagl DAX, Aufenacker TJ, de WJ, Strobbe LJA Systematic review of the effect of external beam radiation therapy to the breast on axillary recurrence after negative sentinel lymph node biopsy. Br J Surg 2010;98(3):326-33.

[30] Gentilini O, Botteri E, Leonardi MC, Rotmensz N, Vila J, Peradze N, et al.
Ipsilateral axillary recurrence after breast conservative surgery: the protective effect of whole breast radiotherapy. Radiother Oncol 2017;122(1):37-44.

[31] Morgan JL, Collins K, Robinson TG, Cheung K, Audisio R, Reed MW, et al, Healthcare professionals' preferences for surgery or primary endocrine therapy to treat older women with operable breast cancer. EJSO 2015;41(9): 1234-42.

[32] Parks RM, Hall L, Tang S, Howard P, Lakshmanan R, Winterbottom L, et al. The potential value of comprehensive geriatric assessment in evaluating older women with primary operable breast cancer undergoing surgery or nonoperative treatment — a pilot study. J Geriatr Oncol 2015;6(1):46-51.

[33] Thomas R, Pieri A, Cain H. A systematic review of generic and breast cancer specific life expectancy models in the elderly. EJSO 2017;43(10):1816-27.

[34] Huisman MG, Kok M, de Bock GH, van Leeuwen BL. Delivering tailored surgery to older cancer patients: preoperative geriatric assessment domains and screening tools - a systematic review of systematic reviews. EJSO 2017;43(1): $1-14$ 